\title{
Interview
}

\section{In conversation with A. A. Baker}

\section{Hugh Freeman interviewed Dr Baker recently.}

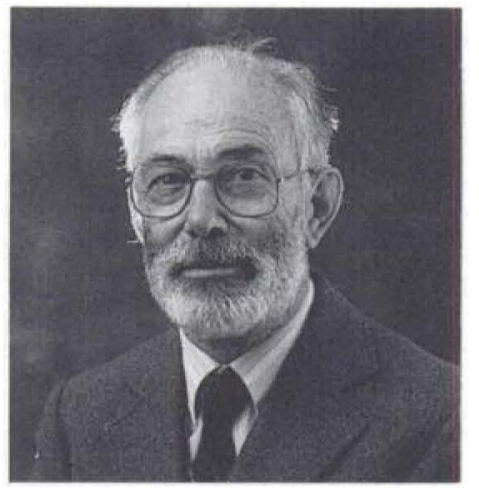

Dr A. A. Baker, CBE, Director, NHS Hospital Advisory Service, 1969-73.

Can I ask about your early life, your education, why you went into Medicine?

I was the first in the family to do so, and I believe this gave me both considerable advantages and disadvantages. The advantages were that I looked at a lot of medical situations afresh, with no previous idea of what was possible or impossible. On the one hand, I missed the background many doctors had - the easy entry into the old-boy network; I've no doubt that at times, this limited my effectiveness. On the other hand, at times it's been an advantage to be quite independent, without feeling any need to be influenced by previous practice or old loyalties.

I became a doctor by accident. I was working for the equivalent of $A$ levels and had a very good biology master, who was encouraging two or three others to go into Medicine. One day, he arranged for three of them to spend a day at Charing Cross Hospital, to see what it was all about. At the last minute, one of them became ill and the master persuaded me to go instead. I didn't really enjoy that day-I was distinctly put off by operations and pathology - but there's no doubt that it stirred something inside me. Eventually, as the same master had a link with 'Mary's, I went for an interview there, and was accepted. Certainly, once in medical school, I found the work so interesting that it wasn't a problem to learn. I read text-books for the fun of it!

As a student, did you have any teaching in psychiatry?

We did. I remember 12 lectures which, if anything, put me off. I thought that if this is what psychiatry really is, I'm not impressed. We also had one or two visits to mental hospitals, but these were disillusioning: sometimes patients were put on display - rather like some television programme - and I felt that this was wrong, demeaning to both patient and interviewer. On the other hand, though, I had become very interested in psychosomatic medicine, after reading Katharina Dalton. At the end of my time at St Mary's, we had end-of-term competitions, with small cash prizes; I was terribly hard up, I suppose as many students are, so I had a go at them just for the money. I won the prizes in paediatrics and psychiatry, and this probably reinforced my feeling that psychiatry might be a field for me.

\section{What happened when you qualified?}

My first house job was partly orthopaedics and partly ENT, and there is hardly any mixture that could be more off-putting to a young doctor. But I was extraordinarily lucky, because in June '44, I was suddenly removed from the job to Park Prewett Hospital, Basingstoke, where a surgical service for D-Day casualties had been set up. There, I volunteered to work on Alexander Fleming's Penicillin Unit and had some of the most interesting, exciting work any young doctor could possibly want. Seeing the early results of penicillin in battle casualties, experiencing the difficulties involved, and working with people who were very stimulating made me think hard about surgery. However, all good things come to an end and when this post finished, I had to look round again. I met Professor Stokes - he was Dr Stokes then-the Deputy Superintendent at the Maudsley. He thought I should apply for a job there, and so I did.

\section{What was your experience of the Maudsley?}

When I was accepted, I went to Mill Hill, where one half of the Maudsley had been evacuated. Again, I was very lucky in being appointed houseman to Eric Guttman, who was a neuro-psychiatrist. As a person, he was so helpful and supportive to a young doctor, 
particularly one like myself who was naive, incompetent, and ignorant. I was indebted to him and always will be. I was keen to take a training analysis in those days, but when I told him about it, he said to me, "Well, you may have decided, but think about it for another week, and during that time, carefully observe your colleagues here who are themselves analysts or have been analysed". So I did, and I must admit that a study of fellow psychiatrists, all of them very senior of course, was very interesting! At the end of it, I decided I would not have an analysis; most of those who had been analysed seemed to me too detached from their patients. If something went wrong or a patient disappeared or committed suicide, there was always an intellectual explanation.

\section{What did you do next?}

After Mill Hill and Guttmann, I went to Dartford with Max Jones, treating ex-POWs. Again, this was a very different experience and some of my early attitudes to group therapy were developed there, but I was still very green and naive and didn't understand a lot of what was happening. As a complete contrast, I then went to Belmont, where I was registrar to Sargant. I was very impressed - not by his polypharmacy, which I think one had some reservations about even under his immediate mantle and in awe of his personality, but by the care he took over individual patients, the interest he showed in them, and the detail he would go into to understand their lives and how medication would influence them. I learnt a lot from him, not so much about polypharmacy as about relating to patients and how to help them. I was then conscripted and went into the Army.

\section{How did you find that?}

To my surprise, I enjoyed it and found a lot which was useful from the point of view of gaining psychiatric experience. I became Area Psychiatrist at Aldershot and from there, curiously enough, learned a great deal about family psychiatry, about running an out-patient clinic, and about organising my time. The pressure of work - I was the only Army psychiatrist for a large area-was tremendous. So I learnt that I had to know what the priorities were, how to get a quick history, who to contact, and how to make a decision. I also became involved in Army Apprentices Schools, wrote two or three papers on their problems, and became quite interested in the difficulties of adolescents and how to distinguish between adolescent reactions and illness in adolescents.

I also visited a number of Army 'glasshouses', and did a paper on the relationship between deserters and civilian crime. This was at a time when there was interest in an amnesty for Army deserters, and I was able to show that a proportion of them who had previously been honest citizens, went on to commit crimes while on the run, because it was the only available way of life. If there had been an amnesty, they would have returned home to ordinary work. This paper was not acceptable to the Army, and I was told I was still bound by the Official Secrets Act. I applied for permission to publish every year for ten years, and eventually got it, by which time, of course, the whole thing was irrelevant.

\section{You were then demobilised?}

Yes. I returned to Belmont, and worked on Max Jones' unit, which was now dealing with psychopaths. He was away for a year, and I enjoyed it more then than when he was there, because we didn't always see eye to eye. I was now beginning to feel much more self-confident and had a better idea of what psychiatry was about. The unit helped me to understand my own behaviour in a group, as well as group and staff interactions, but I was unimpressed by the actual results. In hospital, many patients seemed better, but with follow-up for a year, their outcome was generally poor. I was then senior registrar, and it was pointed out to me by Walter Maclay that since my experiences were limited to neuroses, groups, and psychopaths, I must get experience in mental illness.

\section{How did you do that?}

I went to Netherne with Dr Freudenberg, and again, how lucky I was. What a nice man to work with and how helpful and supportive he was to me, being green in that field. I remember my first day there. I started off on the ward for neurotic patients with a ward round and a group session, spending about an hour and a half. I was then told I would have to spend the next hour on a long-stay ward. So I went there and said to the sister - it was all locked up of course "What do I do here?" She said "Well, there are 50 ECTs waiting for you"! They were laid out in rows, with a screen between each: you just went from one to the next. There was no anaesthetic; you just pressed the button, waited until they finished convulsing, and went on to the next.

Again, I learned a lot at Netherne from the mistakes I made - such as the errors in judging what long-term psychotics might do if you let them out. Another stroke of luck was in 1952. Freudenberg had been to the Continent and had brought back some chlorpromazine, which he gave me to try. The first patient I gave it to was an elderly lady with dementia, who had had an operation and was tearing at her stitches. Since she seemed moribund, I thought at least I could do no harm, so I gave some intramuscular chlorpromazine and to everybody's surprise, her restlessness ceased, she stopped tearing out her stitches, recovered from her pneumonia, and proceeded to live for some time longer. Thus encouraged, the next 
patient I treated had an acute early schizophrenic illness - a young woman who had attacked the psychiatrist in the out-patient clinic and had been admitted in a very disturbed state. Again I was fortunate, because this young girl responded so well that two days later, I was able to demonstrate her at a clinical conference, to the surprise of all. I then treated a series, gave a paper to the Divisional meeting of the RMPA, and wrote it up in the Journal in 1954. So as far as I know, these were the first British psychiatric cases in which chlorpromazine had been used, and the first paper on it in this country. So Netherne was a rewarding experience.

\section{What came next?}

I had a short spell at St Ebba's, and then became a consultant and deputy superintendent at Banstead. Dr Charlton was the superintendent, and he said to me on the first day, "If you do anything it must lead to improvement."

\section{What did he mean by that?}

Conditions were very bad there. It had been grossly over-crowded during the war, when patients from other hospitals had been put in to clear their beds for casualties. I was told it had been the cheapest of any of the London lunatic asylums, and evidence of that was widespread. I was the only consultant on the female side, which had 1500 beds - seven wards of over 100 a piece, and almost all of them locked. At this point, I felt quite bitter about the training I had had. Nothing, except at Netherne, had prepared me in any way for working out the logistics of the service, of how to allocate time, where to give priority, or how to devise the best way to create a service for the maximum number of patients.

Your training had really been on an apprenticeship basis?

Yes, on the whole. At the Maudsley, I was taught how to diagnose; in fact, there used to be an old crack that if you wanted to have a diagnosis, you went to the Maudsley, but if you wanted to be treated, you went to a mental hospital! A little exaggerated perhaps, but I had to solve some pretty awful problems at Banstead. There was a waiting list for admission, grossly over-crowded wards, and many patients going from the admission ward to a back ward after about a week or two of arrival, because there just wasn't time to work out their problems and try to treat them. So instead of having one ward which took all the female admissions, I split it into three. In a three-storey block, I had the patients aged up to 40 on the top floor, the middle ward had the 40-60 yearolds, and the ground floor had the over-60s, which must have been one of the first psychogeriatric services. Then, in the ward for younger patients, I set up a research programme on first-admission schizophrenics, which compared the results of ECT (giving 20 as a routine course) insulin coma (which was still in use) and chlorpromazine. I used fairly heavy doses of chlorpromazine, to give something like the experience of a coma. Then, I compared the end-results after three months, and followed the patients up for a year. In fact, I rapidly abandoned insulin coma, as too many patients did not complete the course and in any case, the results were not good - many patients were still left with emotional flattening. The results of chlorpromazine and ECT at the end of treatment were very similar, but a year later, those who had had ECT experienced far fewer relapses. I also did research on the treatment of long-stay patients, comparing habit training with ECT and other treatments, and wrote a series of papers with Dr Thorpe, a psychologist. Some of these early papers compared different drug treatments, but others were on the theory and philosophy of double-blind trials, which were certainly not blind to the nurses-some thought the only people who were blind were the doctors!

In your paper on the ECT regime, I wondered at the time why you chose 20 as the standard course? It seems rather high.

It does now, but I have no doubt it was effective. I know from bitter personal experience that to give six or eight treatments to patients with schizophrenia would often relieve the symptoms, but relapse was almost certain. On the other hand, more intensive ECT - if need be administered daily for a week, or certainly three times a week for two or three weeks, and then twice a week and then once a week, up to about 20 treatments, produced very good results, while the relapse rate was dramatically lower than with fewer treatments. Of course, using chlorpromazine and other drugs as maintenance treatment helped to maintain a good remission, once it was obtained. The other thing that made me feel ECT was a valuable treatment in schizophrenia was that the patients had a better affective response at the end of the course, whereas many of them now on long-term medication are somewhat 'flat'. I think this is overlooked in the current feeling that the drugs ought to cure everything.

\section{Do you feel now that ECT was depended on too much} at the time?

Yes, but now it is used too little, partly because of the complications involved in anaesthesia. I followed-up a series (from Netherne and Banstead) of young mothers who had schizophrenia, and found that after a year, not one was looking after her baby. I thought that a very bad end-result, so I started a smail ward for mothers and babies at Banstead, specialising in those with schizophrenia, and those mothers all 
received approximately 20 ECTs. I admitted there a number of young women who had been in other hospitals, including good teaching hospitals, and who had been referred to me as chronic patients, but if I gave them an intensive course of ECT, they emerged bright, able to care for their babies, and with a very different prognosis. In the years of running the unit, every mother left caring for her baby herself, and that is not a bad record over some years. We followed-up all patients ourselves, which makes a tremendous difference.

\section{How did you manage to do that?}

Since we took patients from our own catchment area and also, by a gentleman's agreement, from other parts of the south of London, we could offer an outpatient appointment and follow-up for every one. They nearly all managed to come regularly, but I would not take a patient from further afield. I was able to show that the relapse rate of patients I didn't follow-up personally was roughly double. This work led to a book, Psychiatric Disorders and Obstetrics, which was the first based on British practice.

Could I ask you to describe what the atmosphere was like in a mental hospital in the 1950s?

Yes, dreadful. At Banstead, there were several wards which only took disturbed patients rejected by other wards; this was a very bad system indeed. One of these had 100 or more patients, and when I went round, the hair on the back of my neck would stand up for fear of what would happen: it was not unknown for missiles to fly across the room, or for quite blatant assaults to occur. There was no occupational therapy, and patients just stood or sat around the outer edge of the ward in a state of apathy or tense frustration. The smell of paraldehyde filled the air and some patients were persistently drunk and disorderly on it. Many were in strong clothes - very strong garments which in theory, they couldn't tear, but the reality was that it acted as a challenge to the more destructive ones, who just tore them up the more. On the female side alone, there were 50 or more patients every day who were secluded the whole day, some having been so for months or even years at a stretch. I remember one who had been in seclusion for three years in a padded room-dreadful conditions. Time did not permit going round and assessing everyone. All I did was to ask that before a patient went into seclusion, the nurse should write out a paragraph to explain why, and when the patient would come out again. As a result of this, the number secluded went down dramatically in two or three months to four or five a day, which was manageable and meant they could be individually assessed and treated as needed.
At the other end of the scale was a ward of over 100 patients who were active and ambulant; all had useful jobs about the hospital, in the laundry, the bakehouse and similar places. Many of them had pets, and with only one sister running the ward, it was a very easy, relaxed place; these patients had the benefits of an enormous television screen of about $6 \mathrm{ft}$ by $6 \mathrm{ft}$ - an absolute gem. I went to this ward and had an open meeting and explained to them that I was willing to help contact relatives or friends, to find accommodation, to find work, to make sure they were financially viable, and offer follow-up in the outside world. I asked for volunteers, and had none. So a week later, I did the same again, but suggested that if they were reluctant to talk to me, would they talk to the ward sister? There were still none. After the third such visit, the ward as a whole did a 'round robin', which they sent to the Minister of Health, protesting that I was trying to discharge them! They certainly weren't oppressed or imprisoned.

This particular block was needed for development, so, over a year or so, all the patients on that ward were transferred to others. Without any further effort on my part, many of them left the hospital; they seemed to find relatives that they didn't know existed before, and found jobs. Some were undoubtedly helped by the occupational therapy and factory work we provided, but of the series I followed-up, not one was actually doing work for which he had been trained. They had found a wide variety of jobs, though. One was running a restaurant and wrote me a pleasant letter, thanking me warmly for all the help given her and for allowing her to leave. It was quite clear from the letter that she retained her paranoid delusions unchanged, but a social worker reported that she was functioning efficiently and offering a good service to the public in her restaurant. One of the former patients wrote references for others! Some, of course, were still unemployed and one or two relapsed, having to come back into hospital. At the time I'm describing, though, the system of treatment in psychiatry generally was changing. Outpatient clinics were gaining importance, so that the one I began fortnightly became twice weekly and the availability of treatment there, including out-patient ECT, made a big difference.

\section{Did you have any other professional activities at this time?}

Yes. In 1957, I worked for WHO in Geneva with Llewelyn Davis, a very able architect, and Professor Sivadon from France. We produced the first WHO monograph, called Psychiatric Services in Architecture. Again, I was fortunate at that stage in my career to meet Sivadon, a very modest man, who introduced concepts which helped me to understand the basic principles of providing a service to meet the 
needs of patients. For example, small spaces encourage close relationships. If the patient is severely disturbed, a one-to-one human relationship is needed in a.small area, with feeding by the person undertaking care, and very elementary occupation, almost at baby level. But with progress, patients can begin to deal with a small group of people and form a variety of relationships. They then need less personal care, can develop choices, and later emerge from the small family grouping into a wider sphere of perhaps a whole ward of people. This was described in our book and the early chapters are still worth reading; it formed the basis of the work I did in the Department of Health later on. It also taught me how essential it is to involve an architect in early discussions when planning to build.

\section{What was your next assignment?}

I was writing quite critical articles at that time about the way psychiatry was organised and the defects of the mental hospital system. The Regional Board approached me and said that as some money was available, would I be willing to advise on and if need be run, a psychiatric admission service at St Mary Abbot's, Kensington? This was a very nice opportunity. With an architect called Harry Smith young, alert and quick to pick up what was needed the present unit there evolved. I think we had something like $£ 60,000$, out of which that prefabricated unit was built, and a little was left over to develop another building as a day hospital. It helped me to see how a properly designed building made treatment and the development of good relationships relatively easy.

\section{What were the special features?}

There were a small number of single rooms for very disturbed patients, near to the nursing station, where close contact and individual care by nurses was easy. To follow this were small cubicle-style dormitories for four, five or six people, where the patients moving from individual care could enter an area in which they began to form relationships with a small group of others. The ward as a whole had 30 or so patients, so there were natural groupings in which they could progress from complete dependence and maximum nursing care to a situation of increasing independence, and move eventually into the community. I was also able to show that if this was closely linked to the day hospital, with patients moving from one to the other, both follow-up and admission became easy: you could see some patients at the day hospital and admit them to the ward, or discharge them from the ward to the day hospital. The chief problem for psychiatrists is dealing with patients' anxieties of one sort or another, and the more you can do to relieve these by your attitudes, in the buildings you provide, or the way you run the service, the better. During the four years I was working there, no patient of mine went on to Banstead. It was possible to admit, treat, and discharge a very wide variety of cases, but in those days, one-third were brought in on an Order of one sort or another, a fair number by struggling policemen.

What happened to those patients who had chronic handicaps?

An old saying I used was that you don't have chronic patients, you only have chronic staff. There are certainly patients with long-term disabilities, and you need to adjust your service to make the best use of that part of the patient's personality which is still functioning well. It was at this stage that I found the day hospital invaluable; day hospitals should be willing to carry a proportion of very handicapped long-term patients.

In the late 1950s, it was said by a number of people that the day hospital is really for only short-term cases, while long-term patients should be in day centres

There is certainly a group with long-term handicaps who are better placed in a day centre and managed by social services, but there is also a group of quite severely handicapped patients, still needing skilled management, who have their best chance of maintaining social competence on a day hospital basis. Sometimes it was almost impossible to find accommodation for them until we realised that the people who know best where to find accommodation for patients are other patients. We would say to the group, "Mr or Mrs so-and-so is leaving hospital with nowhere to go. Can you help?"' They'd almost always know who had a spare room, which hotel would tolerate bizarre behaviour, or other relevant information. Patients were often more successful than a trained social worker. We need to look at the assumption in this country that only the professionals have solutions. Sometimes the ordinary public or people with their own handicaps know best. We need to listen to them.

\section{How did your next assignment come about?}

After writing up the St Mary Abbot's experience, I wrote a series of articles with rather provocative titles like 'Breaking up the Mental Hospital' or 'Pulling Down the Mental Hospital'. I was at a social function when Dr Tooth approached me, saying that since I had been so critical of the Ministry of Health, would I be willing to have a go and see if I could do any better! Eventually, I agreed and went to the Department of Health as their Senior Principal Medical Officer.

\section{You came to the Ministry in 1967?}

That's right. I had no previous experience of civil service life or the sort of work expected, though some of it had been explained to me. But I think anyone 
going there had to learn the hard way, by finding out how things are done. I was told my first duty was to protect the Minister, i.e. to make sure that any advice, or anything the Minister said, was in keeping with accepted policies and would not lead to criticism in Parliament. I found to my surprise that there was very little, if any, forward planning for psychiatric services. At first, much of my time was spent either dealing with the problems surrounding addiction or problems of the Special Hospitals. I must be frank now and say that I felt I was wrongly employed.

\section{In what way?}

To set up a drug addiction service based on the NHS was a political decision and one not necessarily based on any medical evidence that I knew. Personally, I feel drug addiction is primarily a social problem with some medical complications, rather than primarily a medical problem. The Special hospitals were then administered from the Ministry of Health and I felt that trying to run a hospital from a distance, without day-to-day involvement, was a mistake. Also, I had to express an opinion on the release or admission of patients to Special hospitals from the documents alone, and this was against my better judgement; I thought I should see a patient before I expressed an opinion. On the other side of the coin, I found a singular lack of planning for future psychiatric practice, an absence of any up-to-date physical plans for new buildings, and an absence of policies to go with them. Eventually, we got together a team to look at future planning for psychiatry and at some point, this got labelled 'Mainstream', because I said that we needed to look at the mainstream of psychiatry and not what I regarded as the frills and outside activities like drug addiction and special hospitals. I don't mean any disrespect to eminent colleagues working in these fields, I am just explaining how I felt personally.

It was only after I had been in the Ministry for some months that I found there was an architectural section, which was also very interested in planning buildings for psychiatry and once we got together, things went ahead very rapidly. We were able to produce a draft building note and draft plans to go with it; with very little modification, these are the basis for current planning for admission wards and the policies that go with them. It has been very interesting indeed to see the psychiatric wards at Worcester, Chase Farm, and elsewhere based on those plans.

Could we go back? It was in 1961 that Enoch Powell first proposed a very drastic reduction in the size of the mental hospital sector to half or less. What was the response from within the Ministry; did they prepare plans for a future service as an alternative for mental hospitals?

No. The Worcester Project should have been initiated in 1961. There was a statement of intent, but none of the detailed planning that was needed to make it possible to close the big mental hospitals. New admission services with day hospital support were not being planned in the numbers that were needed, nor were the policies to go with them. The higgledypiggledy production of new admission services, without adequate co-ordination, was a recipe for failure.

That was what happened?

That was how I saw the development at the time, and of course, in the mental handicap field, it was even worse. There was singularly little forward planning of any kind, either at the Ministry or at Regional Board level.

The two years I spent at the Ministry of Health were difficult ones. I certainly didn't have universal approval from some civil servants, though I had a lot of support from Sir George Godber, the Chief Medical Officer, and some others. However, the Department wasn't primarily a planning organisation. It didn't see the need to solve problems of the future in the way that I did; it was more concerned with covering the day-to-day problems. The situation did begin to change, though, when Mr Crossman came. He was then the Secretary of State for Health and Social Services in the new DHSS - a big, powerful, man, quite willing to express a vigorous opinion on any subject. People either liked him or disliked him; luckily, we got on well. He was very critical indeed of senior colleagues in the Department-sometimes publicly and certainly tactlessly by any standards. There is no doubt whatever that he did the cause of psychiatry, and mental handicap in particular, a great deal of good. He was the only politician I saw who was willing to challenge civil servants on their own ground and argue with them on the need for improvements in the service. For instance, he asked for a list of expenditure on the mental handicap services, and went through it with the senior staff. Much less was spent on these patients than on others. It was said they needed less doctoring, fewer nursing staff(there's a lot of supervision, so they don't need many nurses) and so on, but when it came to diet, he said "Stop! They eat, don't they?" And I think that this insistence on looking at the resources allocated to the under-privileged section of medicine made an impact on the Department. He could be quite frightening when he got into a combative mood, and I think civil servants either had to find good reasons for what was happening or accept that sometimes he was right. Understandably, he put people's backs up, and that also made problems for him. I have no doubt he did begin to change policies significantly and made very senior people in the Department think about their priorities.

How did the Hospital Advisory Service come about?

There were the scandals within the mental hospital service, and particularly the one for mental handicap 
in Wales, when Crossman said that instead of sweeping it under the carpet, he would use it. The report was published and one of the recommendations was for some sort of inspectorate. This eventually became the Hospital Advisory Service, of which I was first Director. The proposal was vigorously rejected by the Department, which didn't like the idea of any sort of organisation looking at the mental health service having the right to go direct to the Secretary of State. They wanted to feel they were the only channel to give advice to the Secretary of State. The post of Director was advertised, but I didn't apply. Crossman was not satisfied with the applicants, and so he took me aside privately and asked me to do it. I had already been told not to apply by a senior colleague in the Department, but the job interested me and I could see its potential. I knew it was possible that at the end of the day, I wouldn't have a friend left in psychiatry, but on the other hand, that there was a real need for something of this kind. Crossman thought that in the past, people had said they didn't know what was going on and therefore didn't do anything. If we did an effective assessment service, people couldn't use that excuse anymore.

So I took on the job, and had four of the most exciting and busy years I have ever had. My only regret is that I didn't do it earlier in my career, because there was so much I learnt in those four years which would have been absolutely invaluable earlier. Mr Crossman was very supportive, keen to make it work, and organised all sorts of meetings, including a vast one with the press; they were very interested and excited. I said that I was very willing to give them a daily review of what we were doing, but it would contain only the good things I found in the service. After that, there were only two who remained - Mr Wilkinson, who maintained contact and did very responsible articles, and the Times correspondent, John Roper. The same thing happened to television. We had a television crew turn up, but when they found they weren't going to see something horrible, they went away and we never saw them again. So those four years were spent visiting every mental hospital, psychiatric service, and geriatric service in England and Wales. I set it up on a multi-disciplinary basis with a consultant, an administrator, social worker, administrative nurse, ward nurse, and at times a GP, occupational therapist, or physiotherapist.

\section{When you started this, it was completely new?}

Absolutely. I developed it entirely in accord with my own ideas. I was appointed in November and had the first team out in February, 1969. I was very lucky with the staff I was able to recruit; only one consultant was a disaster and one to two other staff unsatisfactory, but most of them could see the value of the work they were doing, and found it very interesting and very stimulating. Many of them said, as I have, that if only they'd been able to do it before, what a difference it would have made to their professional lives. I tried deliberately to recruit a wide variety of opinions among consultants; some were superintendents and some were known to be hostile to the superintendent system. Again, with administrative nurses, some were progressive, and some were oldfashioned, so I tried to make sure I didn't produce a stereotyped approach. In the HAS, I tried to make sure the teams had the right variety and that there would be somebody on the team that any hospital staff would talk to. I had five or six teams working, so that visiting them all and looking after the final meetings, was very intensive work indeed, but I enjoyed it enormously, though I had some very disillusioning experiences. Some eminent colleagues who wrote in the Journals and spoke widely at meetings were found to be running very poor-quality services. On the other hand, some modest consultants that one had not heard of were running a very good service indeed.

How effective was the HAS, do you think? What difference did your recommendations make in terms of what actually happened?

I think changes happened at all levels. Certainly at Governmental level, ample evidence was provided for the Secretary of State to use in discussions with the Treasury, as increasing amounts of money were in fact directed towards the longer-stay services. Perhaps more important, though, was the fact that because of these endless reports going through the DHSS, some of them with horrific information, the Department as a whole began to see that there were major problems that couldn't be ignored. So a large number of people at both Departmental and Regional Board level changed their attitudes. For example, when I started the HAS, out of 15 Regional Boards, only two or three had forward plans for their mental handicap services, but by the end of the first year, they all had them. Even before visiting, a lot of things began to happen. In my first report, I quoted a letter from a charge nurse in a hospital which said, "We hear that you are coming next month and already have - and he listed - toothbrushes on the ward, better food, fresh clothing for the patients", and so on. To some extent, this may have been the most valuable result - that people began to think about what they did, why they did it, how they cooperated with other professions, and things of this kind. Hospital staff knew we were multi-disciplinary, and so they had to begin to ask themselves about the quality of their own inter-disciplinary co-operation. Of course, as we were an advisory service, we couldn't make anyone do anything; we never tried to and wouldn't want to. The thing that pleased me 
most was when I revisited a hospital and somebody would come along and say, "of course, we're doing so-and-so. It wasn't your idea, we worked this out for ourselves". Now it gave me more pleasure to hear that someone had accepted my ideas, and thought they were their own, than the feeling that I had put something over on somebody and they had taken it on board just because I'd said so. It's the old story - a man convinced against his will is of the first opinion still. I think we worked as yeast in the dough - by encouraging ideas and development generally. Even hospitals which had had a bad press in the past, always had some good features.

\section{What about national political changes?}

After the 1970 election, Sir Keith Joseph became Secretary of State, and although a totally different person from Crossman, I found him equally supportive. I think he had quite unjustified criticism is the press; he did a great deal for the Health Service while he was there and for psychiatry in particular, but this had been little recognised. When I left the HAS, to my surprise, I found I had more friends than I had ever had in my life before! I have a large correspondence from that time which I still keep because it was quite heartwarming - the goodwill that I personally and the service generally received. However, I think it was indicative of the reluctance the Department showed over the whole function of the HAS that after I left, they failed to appoint another Director for some months. I found this sort of delay and procrastination too common.

\section{What did you do next?}

After leaving the HAS, I was in the pleasant position, domestically as well as professionally, of being able to choose where to work and what to do. I decided I didn't want to live the rest of my life in London and its suburbs, but that I would like to take on a psychogeriatric stint to see what I could make of it.

\section{Why psychogeriatrics?}

I thought it was an underprivileged area of psychiatry - there was the opportunity to do fresh work, something new. I had fairly strong ideas of what I wanted to do, and when a post came up in Gloucestershire, which is a nice county to live in where the way of life is so much pleasanter than Greater London, I couldn't resist it. So for four years I worked in Gloucestershire, developing a psychogeriatric service, and by the end of that time had four day hospitals running, two very active admission wards, some community nurses, and very good support from social services. My policy was to see all admissions before they came in and in general, to admit for a maximum of two weeks. I think that dementing elderly patients begin to become dependent on hospi- tal life after two weeks and find going back home again difficult if they stay longer. So I also agreed with relatives, GPs and others the date for discharge before they were admitted. In general, negotiations for discharge are much easier if you make them before admission, rather than when the patient is inside. We also planned, in detail, exactly what programme would be provided for the patient and what improvement could be expected. I would assume that the day hospital would always have some patients coming in, perhaps daily, who were doubly incontinent and very demented. Those patients sometimes benefit from the service more than the apparently 'easy' ones that the staff were more likely to welcome.

\section{What about those patients who were on their own?}

Sometimes this was a real advantage, because there were no relatives complaining about the nuisance to their own lives. Even those with no relatives always have a supporting group: there are always neighbours, the local Salvation Army, or somebody going in to see old people living alone. Very often, you can mobilise this support and I was able to demonstrate that with an effective community psychiatric nursing service linked to the home helps, we could always get the old person up in the morning and get them to the day hospital, where we could give them a bath, redress them, feed them, and see them home at night. The most disorientating thing for the elderly is being away from their home base overnight and waking up in strange surroundings. So with day hospital support, we could manage the most difficult of the elderly dementing patients if we wanted to, but many were admitted. I was admitting 400 patients a year, as well as dealing with a lot of patients in the day hospital service. I was also doing up to 500 miles a week, visiting various places on a fairly routine basis, and knew I simply couldn't keep this up indefinitely.

\section{What was to come next?}

I had thought about taking retirement at 55 for some years and the more I thought about it, the more appealing it looked. I realised I was beginning to burn myself out - the work with the HAS had been very intensive indeed - probably the hardest period of work in my life - and in Gloucester I was the only consultant doing psychogeriatrics for the whole area. The end-result was that I decided to retire at 55. I also began to take some of the holidays which I hadn't done over the years, and to indulge my interests in gardening and fishing. However, the first year after retirement did not work out as expected, because I found as soon as you are retired, everybody begins to say "Ah, now you are retired, will you please do a locum, a lecture, or something or other". The first year was very busy indeed, but after that, I took a more positive line and cut my working time to 
about five sessions a week. This was mostly for social services and particularly giving advice on the management of children and adolescents, which is a very old interest of mine that re-surfaced when the opportunity arose. Then, after some years, we decided for domestic reasons, to retire to Devon, and for the last few years there, I have worked two sessions a week and done occasional medico-legal work. I feel I have been a singularly fortunate and happy man in my profession.

From your present position, what do you feel about the ways things are going now - how psychiatry has developed in recent years, and the way it seems to be going at present, with Griffiths and the other changes?

Personally, I'm optimistic and hopeful. In 1984, with Dr Reardon and Dr Rogers, we did a series of visits to psychiatric units in general hospitals. This was written up by the HAS and called The Changing Pattern of Care in Psychiatry. It demonstrated very clearly that there are a lot of young, energetic psychiatrists with both new ideas and the ability and the courage to implement them, and that many interesting new services are developing. I've no doubt that psychiatry has changed dramatically and is still changing; it is necessary for the young men and women in psychiatry to have the courage of their opinions and to produce new ideas and to implement them. I was lucky in my career, and could do this. I have no doubt that there are many other, more able people who could do the same and better. I'm well aware of the current frustrations with money shortages, the need to fit in with management policies, and managers who may not even understand psychiatric needs. But I still think there are ample opportunities for someone who is willing to look for them, to convince people and to talk their way into a situation where things can be done. This is certainly the case in developing a service to general practice, and community work generally.

\section{Do any trends worry you?}

I am uneasy about a number of trends; in particular, I think the legal threat which hangs over doctors nowadays makes them practise defensively. I am sure this is one reason why ECT is not used as frequently or as freely as it should be, and I think this deprives many patients - schizophrenics as well as depressives - of their best chance of a good-quality recovery. The present tendency to assume that every patient must have a detailed plan on leaving hospital doesn't make allowance for human nature. All these plans need to be flexible and particularly flexible in response to the patient's wishes, as opposed to what staff may feel is good for them. I still think psychiatry is a cinderella profession and runs the risk of being outvoted and out-manœuvred by other professionals. This, of course, holds true for geriatrics too. Yet I think psychiatrists complain too readily about their diffculties in relationships with other professions, particularly social workers. As I see it, a psychiatrist's job is not just to make good relationships with patients, but also with other professionals. If he can apply his skills to one, he should apply them to the other. I think that makes life much easier and much more interesting.

\title{
Compulsion in psychiatry: blessing or curse?
}

\author{
ANATOLIY KoRyagin, Am Brunnenbächli 8, CH-8125 Zollikerberg, Switzerland
}

It is common knowledge that psychiatric patients sometimes need to have compulsory measures applied to them for the safety of themselves and of others.

In the Soviet Union compulsory measures have always been used with mentally ill persons by way of compulsory psychiatric examination and compulsory treatment.

At present there is much talk of reforms in the socio-political and economical life of the USSR. Many people know already of the new "Regu- lations" on handling mentally ill persons, in force since 1 March 1988.

This is what it says in item 9 of the said Regulations:

"A person committing actions that give sufficient reason to assume the existence of a pronounced mental disorder in him, who violates the public order or the rules of socialist communal life and/or represents an immediate danger to himself or his associates, may be submitted to an initial examination without his consent or the consent of his relatives or legal representatives." 